\title{
Predicting UK Business Cycle Regimes
}

Chris R. Birchenhall, Denise R. Osborn and Marianne Sensier

\author{
Centre for Growth and Business Cycle Research \\ School of Economic Studies \\ University of Manchester, Manchester, M13 9PL, UK \\ e-mail: Marianne.Sensier@man.ac.uk \\ web address: http://www.ses.man.ac.uk/cgbcr/
}

$27^{\text {th }}$ January 2000

Second Draft

Please do not quote without permission 


\begin{abstract}
Following on from the work of Birchenhall, Jessen, Osborn \& Simpson (1999) on predicting US business cycle regimes we apply the same methodology to construct a one period ahead model of classical business cycle regimes in the UK. Birchenhall et al (1999) used regime data implied by the NBER dating of peaks and troughs. In the UK there is no comparable dating committee and our first task is to date the UK peaks and troughs. Application of a simple mechanical rule based on changes in GDP produces a set of acceptable turning points, with one exception that is attributable to the 3-day working week in 1974. Based on data from 1963 to 1999, we date three business cycle peaks at 1973 Q3, 1979 Q2 and 1990 Q2 together with troughs at 1975 Q3, 1981 Q1 and 1992 Q2. Starting with a number of real and financial leading indicators, several parsimonious one-quarter-ahead models are selected largely on the basis of the SIC criterion. A number of interesting results emerge from this investigation. A real M4 variable is consistently found to have predictive content. One model that performs well combines this with UK and German short-term interest rates. The role of the latter variable emphasises the open nature of the UK economy.
\end{abstract}

JEL classification: C22, C32, E32, E44.

Keywords: business cycle dating, financial variables, leading indicators, logistic classification models. 


\section{Introduction}

Both policy makers and private agents have a serious interest in the occurrence of recessions in economic activity and thus show an interest in leading indicators that help in anticipating the onset of recession and recovery. The history of leading indicators dates back to Burns and Mitchell's (1946) discussion of "classical" business cycle phases in the US.

Leading indicators for the US economy were produced by the US Department of Commerce over a long period, with this system now maintained by the Conference Board. This methodology is based on combining a range of individual leading indicators into a single composite indicator. Green and Beckman (1993) discuss the methodology used, but this may be summarised by saying that it depends on averaging across individual leading indicators in order to extract the common predictive signal. Stock and Watson $(1991,1993)$ have also produced a composite leading indicator for the US using a related, but more sophisticated, methodology. These US leading indicators are traditionally associated with the so-called classical business cycle regimes of recession and expansion in real activity. That is, they are designed to signal in advance periods of decline in overall activity (recessions) in comparison with periods of overall growth (expansions).

In the UK the Office for National Statistics (ONS) had a system of business cycle leading indicators until early $1997^{1}$. These were designed to lead the growth cycle phase of UK gross domestic product (GDP), where growth cycle phases refer to expansion and contractions relative to a long run trend (Moore, 1993). The OECD also produces composite leading indicators for the growth cycle in many countries (Nilsson, 1987). One important difficulty with any growth cycle analysis is that it is based on a definition of trend and such definitions are essentially arbitrary. It is also arguably the case that policy makers and private agents are more interested in absolute declines and expansions in activity than in growth cycle measures. For these reasons, this paper concentrates on classical business cycles for the UK and not growth cycles.

\footnotetext{
${ }^{1}$ These are now being produced by NTC Research, telephone 01491418625.
} 
Many papers have analysed the forecasting information contained in the composite indicators mentioned above. A number of recent studies have focused on the role of individual leading indicator variables, in particular financial ones, sometimes comparing the performance of a range of variables. For example, Estrella and Mishkin (1998) utilise a probit model (based on information from financial and real macroeconomic variables, together with composite indicators) to forecast recessions in the US GDP. They find that the best out of sample predictor beyond one quarter is the term structure of interest rates (the interest rate on long-term bonds minus the short-term interest rate). Using a more conventional linear approach, Plosser and Rouwenhorst (1994) find strong and positive association between the term structure and subsequent growth in industrial production for the US and Germany. Further empirical evidence by Roma and Torous (1997) suggests that the US term structure is relatively steeper at business cycle troughs and flatter at business cycle peaks. In recent analyses relevant to the UK, Andreou et al (1999) examine the role of various financial leading indicators while Camba-Mendez et al (1999) adopt an automatic approach to forming composite leading indicators for forecasting the GDP growth of European countries using financial variables.

This paper follows the work of Birchenhall, Jessen, Osborn \& Simpson (1999), henceforth BJOS, to construct a composite leading indicator for classical cycles in UK GDP. Our indicator is constructed using a different approach to the composite indicators mentioned above. Its value is a number lying between zero and one, which can be interpreted as the probability that the economy will be in an expansion next period, alternatively one minus the indicator can be interpreted as the probability that the economy will be in a recession. Its construction is based on logistic regression where the dependent variable is a zero/one dummy variable identifying recessions and expansion regimes in the economy. BJOS had the luxury of a well-established set of dates for peaks and troughs in the US economy, namely those published by the NBER Dating Committee. There is no matching set of dates for the UK and this paper offers a set of dates for the peaks and troughs for the classic cycle in UK GDP before constructing the leading indicator.

The rest of the paper has the following structure. Section 2 discusses the dating of the classical cycle in UK GDP. Section 3 introduces the leading indicator 
data from which the composite indicator is constructed. Section 4 briefly outlines the methodology developed in BJOS to construct the composite indicator. Section 5 presents the results from applying this methodology to the regimes implied by the dates presented in Section 2. Section 6 offers concluding remarks.

\section{Dating Classical Cycles in UK GDP}

Business cycle dating has generally been performed on US data, with Boldin (1994) comparing the performance of various approaches. Dating exercises which have been undertaken outside the US based on the concept of the classical business cycle include Artis, Kontolemis and Osborn (1997) for monthly G7 and European industrial production, while Harding and Pagan (1999) date the GDP cycles of the US, UK and Australia. Both of these papers use procedures based on the Bry and Boschan (1971) algorithm. The principle aim of this paper is to provide a UK business cycle leading indicator, not to provide a robust methodology for dating turning points. Therefore, we side-step the dating issue and apply a simple mechanical rule to UK GDP in order to produce a set of acceptable turning points.

The following rules describe how turning points were identified in UK seasonally adjusted quarterly GDP (this is an index measure at market prices) over the sample 1963 to 1999 . Table 1 defines a formal description of the rule where $Y$ is GDP. In words this implies the following.

Peaks: Period $t$ is a peak if the following are true.

1. The peak value is no less than the previous 4 quarters.

2. The peak value is no less than the following 4 quarters.

3. The peak value is greater than the following 2 quarters.

Troughs: Period $t$ is a trough if the following are true.

4. The trough value is no greater than the previous 4 quarters.

5. The trough value is no greater than the following 4 quarters.

6. The trough value is less than the 2 following periods. 


\begin{tabular}{|c|c|c|}
\hline & Peak & Trough \\
\hline 1 & $\Delta_{\mathrm{i}} \mathrm{Y}_{\mathrm{t}} \geq 0$ for $\mathrm{i}=1, \ldots, 4$ & $\Delta_{\mathrm{i}} \mathrm{Y}_{\mathrm{t}} \leq 0$ for $\mathrm{i}=1, . ., 4$ \\
\hline 2 & $\Delta_{\mathrm{i}} \mathrm{Y}_{\mathrm{t}+\mathrm{i}} \geq 0$ for $\mathrm{i}=1, . ., 4$ & $\Delta_{\mathrm{i}} \mathrm{Y}_{\mathrm{t}+\mathrm{i}} \leq 0$ for $\mathrm{i}=1, . ., 4$ \\
\hline 3 & $\Delta_{1} \mathrm{Y}_{\mathrm{t}+1}<0$ and $\Delta_{2} \mathrm{Y}_{\mathrm{t}+2}<0$ & $\Delta_{1} \mathrm{Y}_{\mathrm{t}+1}>0$ and $\Delta_{2} \mathrm{Y}_{\mathrm{t}+2}>0$ \\
\hline
\end{tabular}

Table 1: Rules for Dating Peaks and Troughs

Applying the rule to UK GDP resulted in the turning points in Table 2 that are accompanied by the cycle duration in quarters. Here there is a clear asymmetry between duration of expansions and recessions.

\begin{tabular}{|c|c|c|}
\hline Date & Peak or Trough & Duration (quarters) \\
\hline 1973 Q3 & Peak & 31 \\
\hline 1974 Q1 & Trough & 8 \\
\hline 1975 Q3 & Trough & 15 \\
\hline 1979 Q2 & Peak & 37 \\
\hline 1981 Q1 & Trough & 8 \\
\hline 1990 Q2 & Peak & \\
\hline 1992 Q2 & Trough & \\
\hline Trough at 74Q1 rejected as a distortion due to 3 day working week & \\
\hline \multicolumn{2}{|c|}{ Table 2: UK Classical Turning Points in UK GDP } \\
\hline
\end{tabular}

Having decided on the peaks and troughs all time periods can be classified as either one of expansion or one of contraction. Periods of expansion start with the period following a trough and run up to and include the next peak. Periods of contraction (or periods of recession) start with the period following a peak and run up to and include the next trough. 

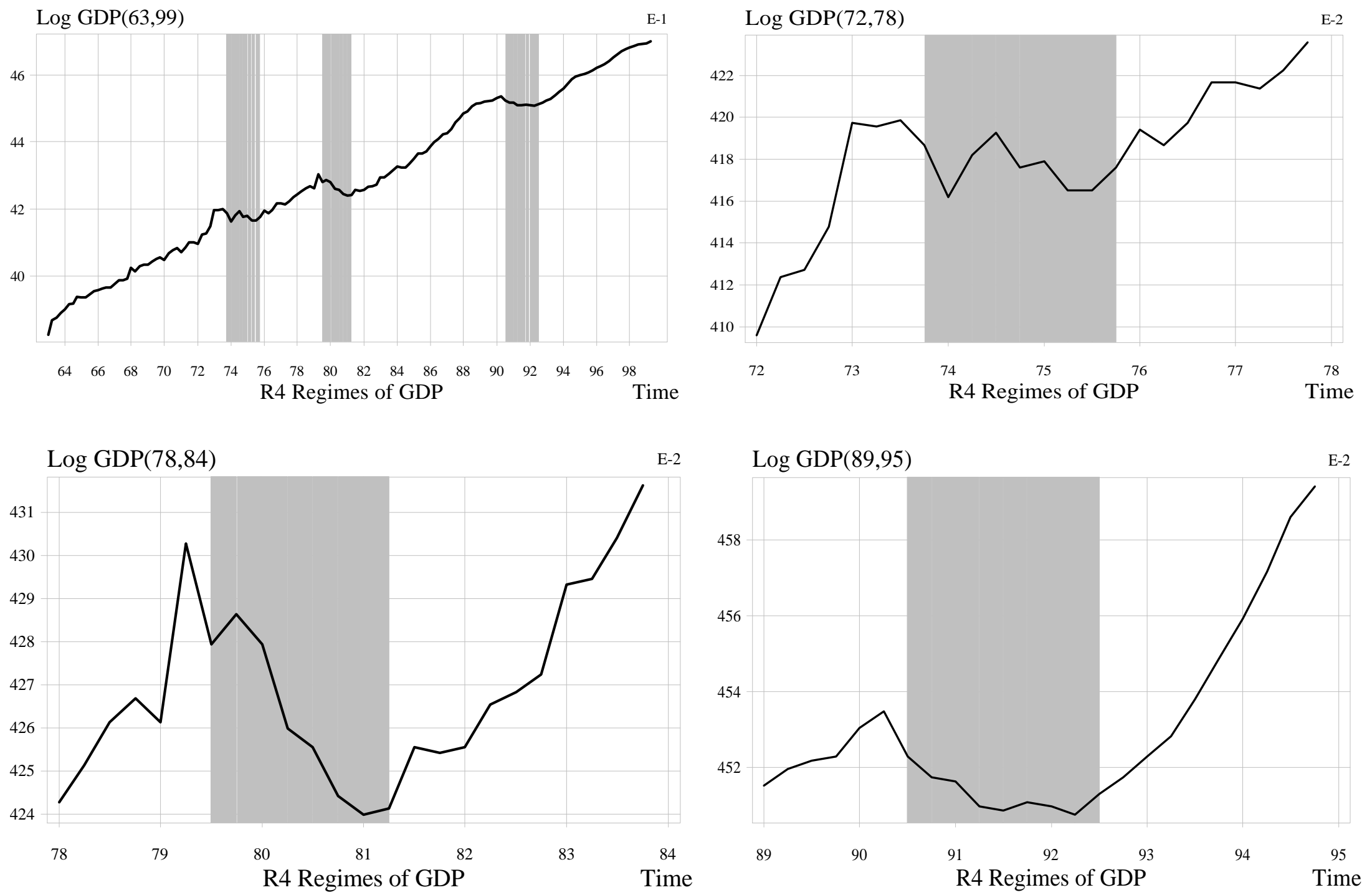

Figure 1: Plots of GDP 
The graphs in Figure 1 show the full sample of the logarithm of UK GDP then each of the recession sub-phases. Note the vertical axis is the natural logarithm of GDP multiplied by 10 in the first graph and multiplied by 100 in the three regime graphs. A word on the line plots and shading is also in order. A point lying on the vertical line marked 79 represents the value of GDP in the first quarter of 1979. That is to say the observation for a variable is plotted at the start of the interval that represents that quarter. The shaded areas represent recessions and thus cover the periods that start in the quarter following a peak up to and including the next trough. For example, the second recession includes the quarters running from 1979 Q3 up to and including $1981 \mathrm{Q} 1$. In the graph for the second recession the shaded area starts at 1979 Q3 and reaches out to 1981 Q2 as this point marks the end of 1981 Q1. The value of GDP at 1981 Q2 marks the end of the recession, not the observation at 1981 Q1.

The reader's attention is drawn to the first recession, which the rule suggests starts at 1973 Q3, but offers two subsequent troughs namely 1974 Q1 and 1975 Q3. The first trough is rejected on the grounds that the low value of GDP in 1974 Q1, and the subsequent rises in 1974 Q2 and 1974 Q3, reflects the impact of the 3-day working week associated with a miner's strike. While this judgement removes the difficulty arising from the two adjacent troughs it has to be suggested that the timing of the start of this recession is not straightforward and some uncertainty remains. In a similar vein the rise in GDP in 1979 Q4 and fall in 1980 Q1 suggest the dating of the onset of the second recession is not clear-cut. Such qualifications to the dating of these recessions is not used in the construction of the composite indicator, rather the construction of the models assumes the regimes are known with certainty. The reader will need to keep this in mind when assessing the indicators offered.

Referring to the authoritative work of Dow (1998) these three recessions are those identified by him as 'major recessions' for the UK. As Dow is essentially looking for growth recessions the precise dating will differ, but the three classical recessions identified above map broadly onto matching recessions in Dow's work. Dow attributes the first two of these recessions at least partly to external events (especially the OPEC oil price rises), whereas the third is viewed as having its origins purely in domestic factors. 
The first recession in Britain 1973-75 was preceded by a large injection of government spending into the economy known as the 'Barber Boom' named after the Chancellor of the Exchequer at the time. Dow (1998) describes how between 1972 and 1973 total final expenditure rose by nearly 9\% and was accompanied by a boom abroad that led to a rapid rise in exports. The recession followed the boom and was also the reaction to the oil price shock and a rapid tightening of monetary policy that in turn was a reaction to the accelerating inflation. The recession was exacerbated at the beginning of 1974 by the effect of the 3-day working week. This was when the government had to restrict industry to a short working week because a coal strike had reduced coal supplies to power stations at the end of 1973 in the so-called 'winter of discontent'.

The second recession 1979-81 was attributable to the rise in the price of oil for the second OPEC shock but this was exacerbated by a large exchange rate rise. This practically stopped export growth so was largely deflationary. The 1979 budget was also very deflationary with cuts in fiscal policy and tightening of monetary policy by the Conservative government as they were trying to control the growth of broad money; this was targeted between 1976 and 1986.

The third recession we identify as 1990-92, Dow dates as longer from 1989-93 when growth was below trend. Dow suggests that the expansion of the 1980s should not only be attributed to financial deregulation as there was a gap of five years between the removal of lending controls and the time when credit creation started to accelerate. Instead Dow attributes the credit boom to the two dynamic developments the growth of pervasive optimism about future prospects and the erosion of prudential standards. Dow concludes that the recession was not due to exogenous shocks, like the previous two recessions, but was entirely due to a reversal of the over-confidence that had been built up in the preceding boom years. This recession was preceded by unsustainable increases in asset prices, property prices and equity prices, these crashed because of a loss of confidence and expectations. 


\section{Leading Indicator Data}

The events described previously that lead to the recession eras were varied in nature and involved the UK operating as an open economy. We will therefore analyse a number of domestic and international leading indicators for their performance with predicting the recession dates as given in Section 2 for UK GDP. Essentially we are looking at a variety of nominal and real variables that are deemed to be important in explaining the real economy.

We were led by previous studies for the full range of data that we analyse. Andreou et al (1999) find strong evidence for financial variables having leading properties and Simpson et al (1999) investigate financial and other variables for modelling recessions in UK GDP with a Markov-switching model. Furthermore Binner et al (1999) find useful leading indicator properties of UK M4 for inflation. Of this range of variables we consistently found that inflation and a subset of financial variables survived the selection process, with this subset being broad money, stock prices and interest rates. There is also strong evidence from the effect of international variables in the form of US stock prices and German interest rates. Variables that were eliminated early on were domestic consumption, dividend yields, exchange rates, housing starts, house price index, CBI change in optimism measure and US short-term interest rates. All the variables that we analyse are detailed in the data appendix at the end of this paper with the abbreviation, description, sample dates, source and transformation used in the modelling. We transform money, stock prices and the GDP deflator data by taking logs and then an annual difference to smooth the data $^{2}$. For the interest rate series we analyse the UK treasury bill yield (TBY) as the short rate, 20 year par yield on British Government Securities for the long rate (LR) and then the difference of these is the term structure (LR-TBY). Graphs of TBY and the German short-term interest rate series (the FIBOR) are shown at the top of Figure 2, with recession periods shaded.

\footnotetext{
${ }^{2}$ Our experiments investigated the use of one and two-quarter differences, but the annual difference produced better models.
} 
$\operatorname{TBY}(63,99)$

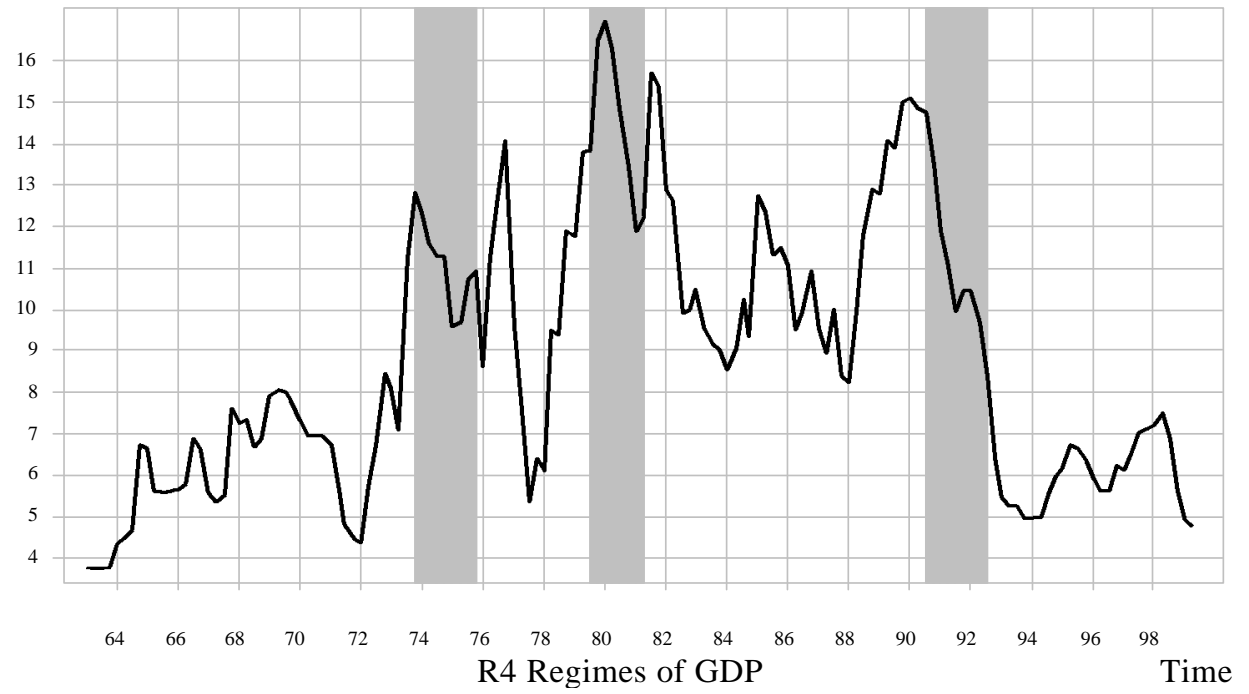

$\operatorname{TS}(63,99)$

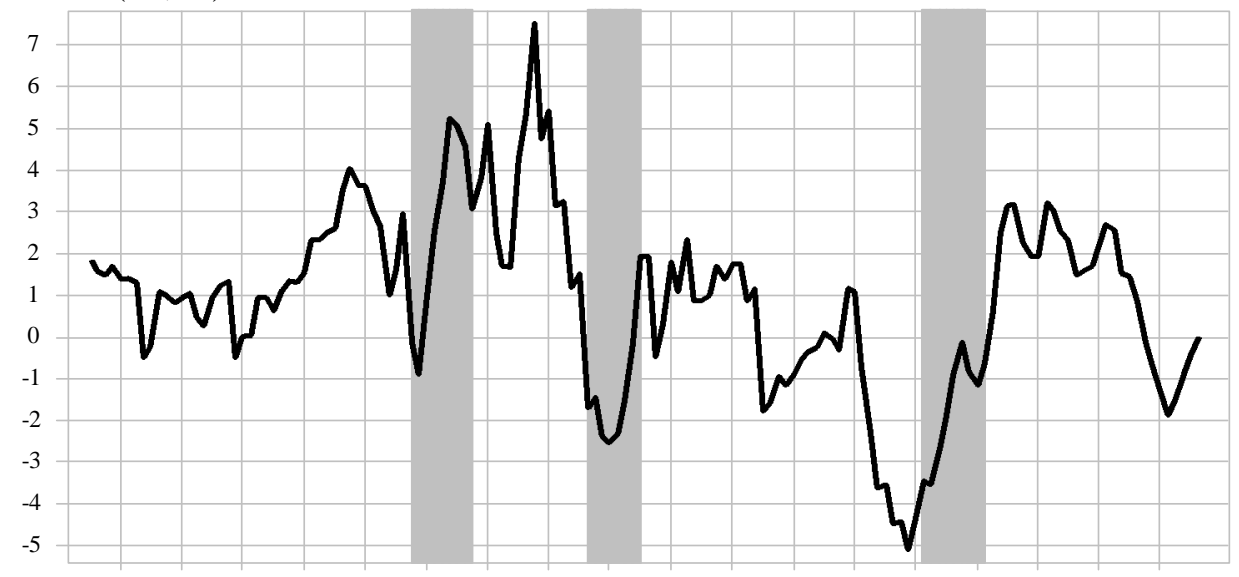

$\begin{array}{llllllllllll}64 & 66 & 68 & 70 & 72 & 74 & 76 & 78 & 80 & 82 & 84 & 86 \\ & & & & & & \text { R4 } & \text { Regimes of GDPIndex }\end{array}$
FIBOR $(63,99)$

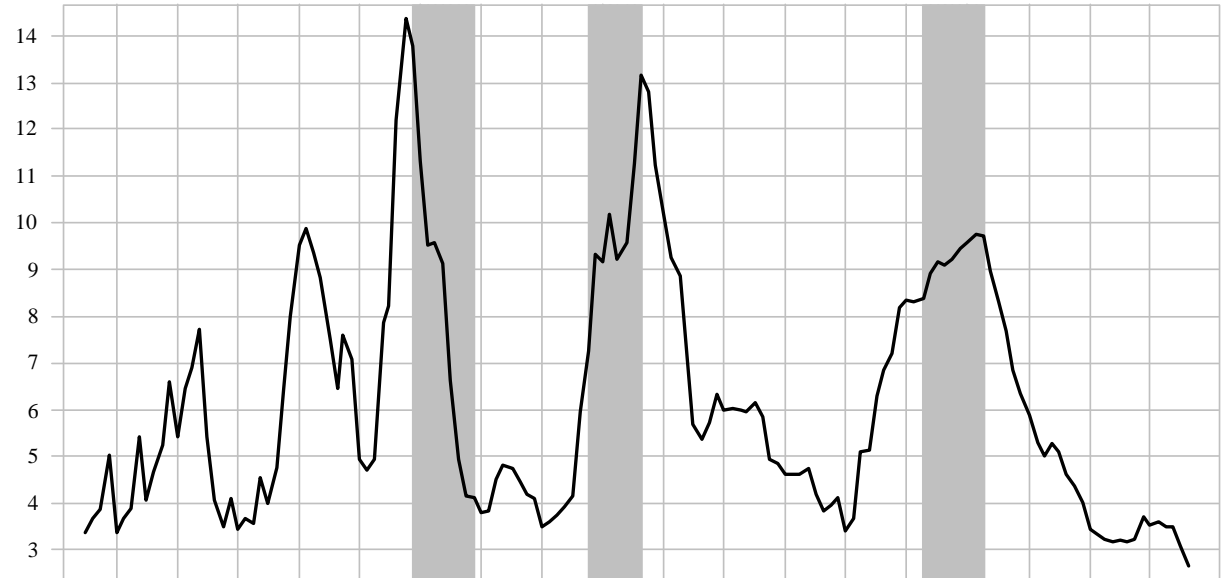

$\begin{array}{llll}64 & 66 & 68 & 70\end{array}$

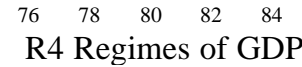

$\operatorname{RTS}(63,99)$

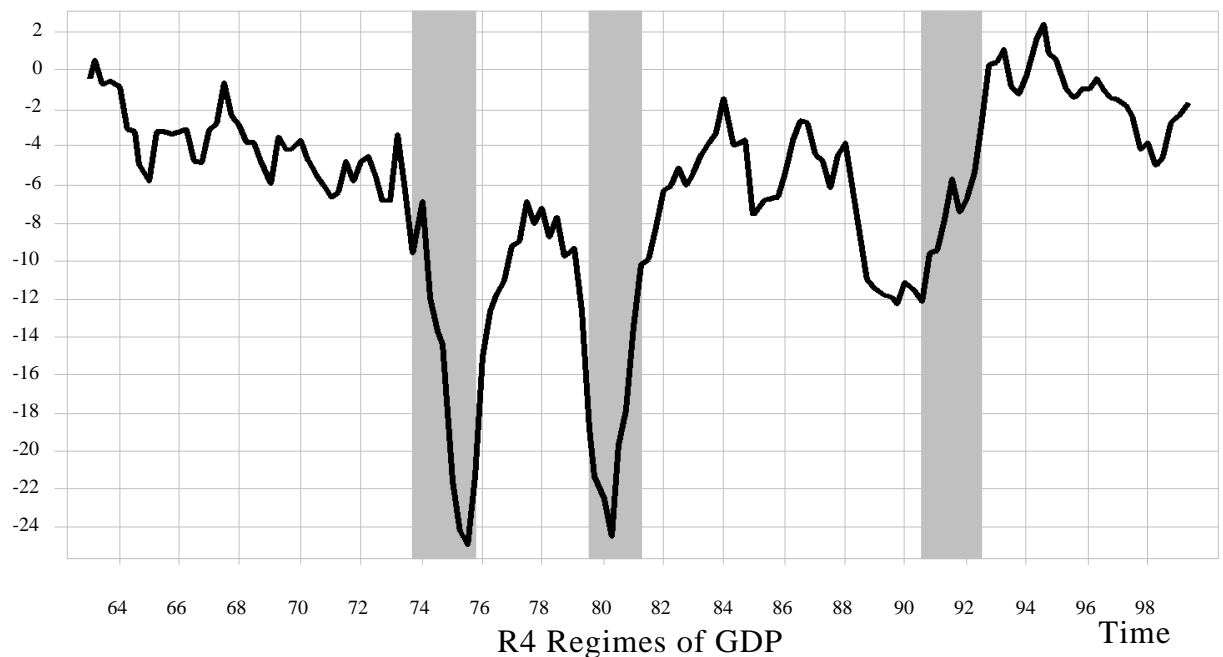

Figure 2: Leading Indicator Plots 


$$
\text { D4LnRM4(63,99) }
$$

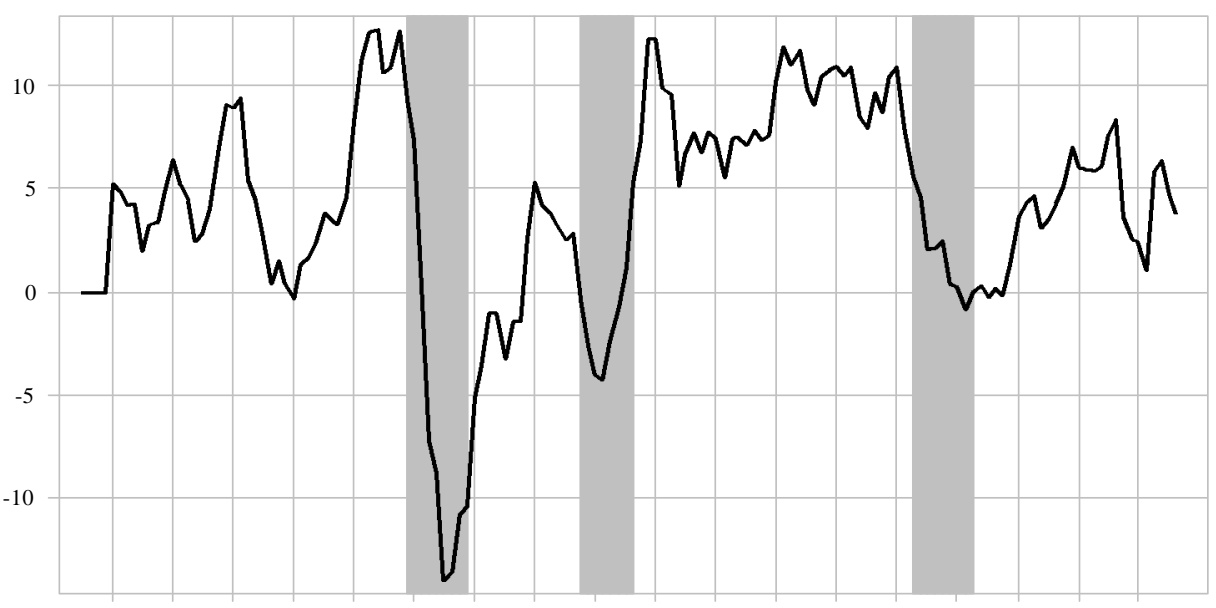

\begin{tabular}{ccccccccccc}
64 & 66 & 68 & 70 & 72 & 74 & 76 & 78 & 80 & 82 & 84 \\
R4 & & & \multicolumn{1}{c}{ Regimes of GDP }
\end{tabular}

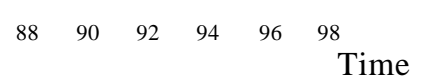

D4 $\log \operatorname{RSP}(64,99)$

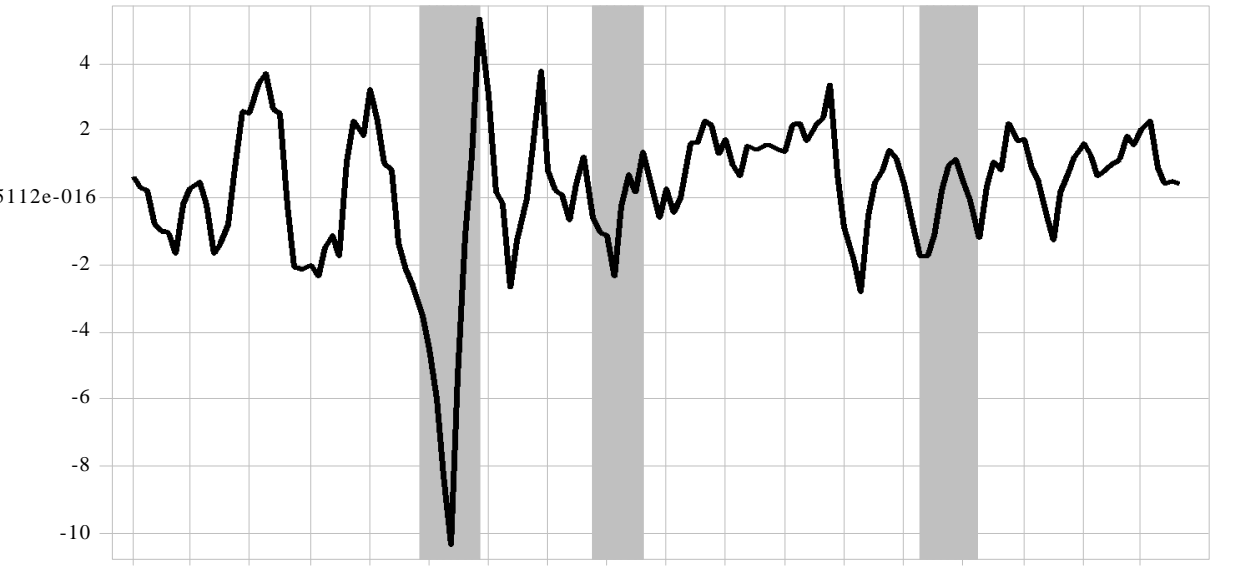

$\begin{array}{rlllllllllllllllll}64 & 66 & 68 & 70 & 72 & 74 & 76 & 78 & 80 & 82 & 84 & 86 & 88 & 90 & 92 & 94 & 96 & 98 \\ & & & & & & \text { R4 Regimes of GDP } & & & & & & & \end{array}$
D4 D4LnRM4(64,99)

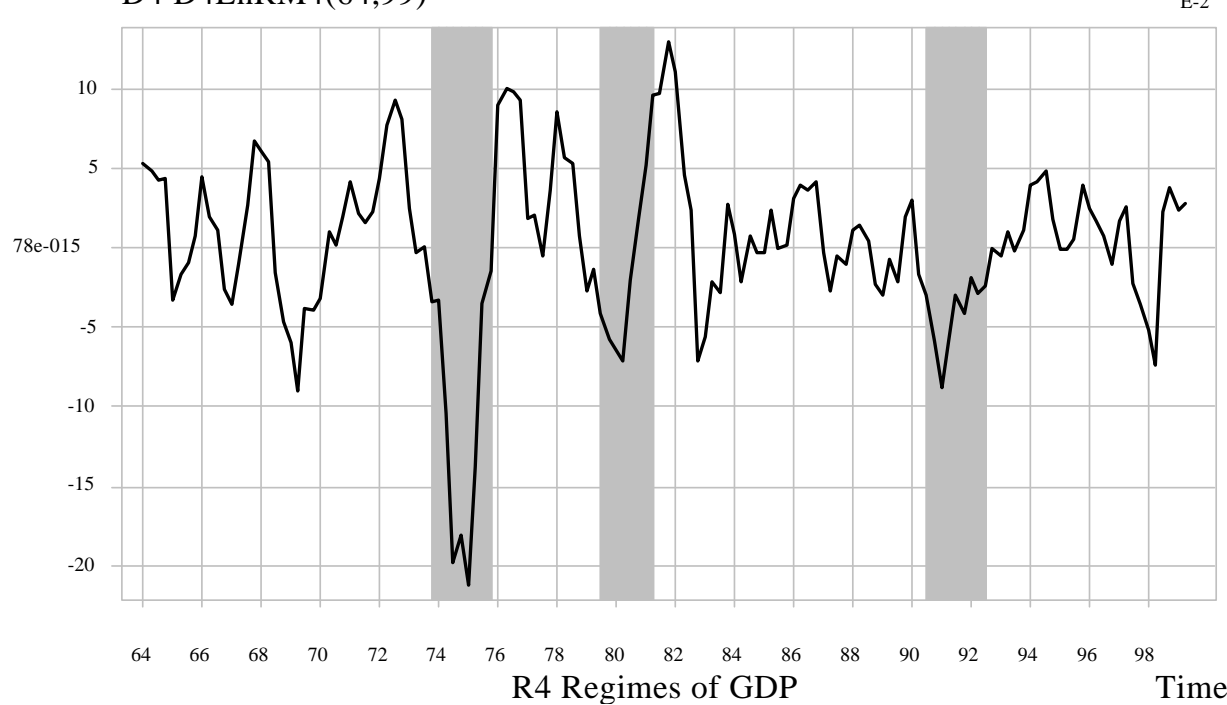

D4 Log US S\&P $500(64,99)$

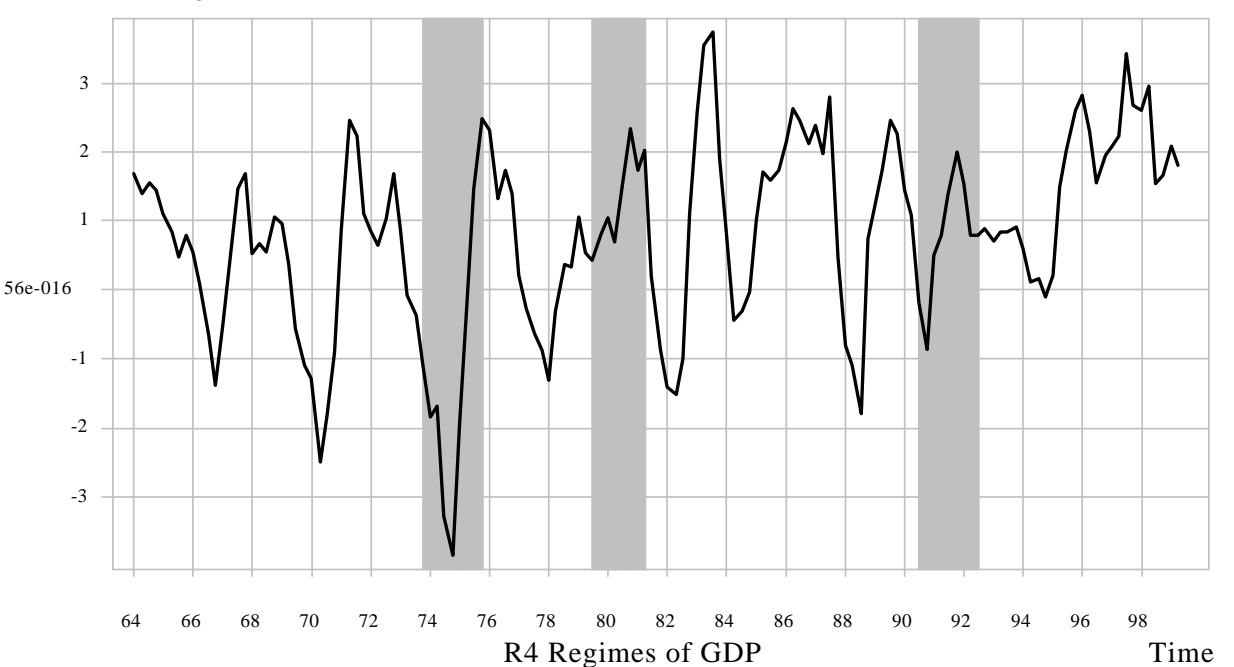

Figure 3: Leading Indicator Plots 
To construct the real variables the nominal series is divided by of the GDP deflator. The term structure and the real term structure (RTS i.e. the long rate minus short rate minus inflation rate) are shown in Figure 2. "Real M4" (RM4) is created by dividing the broad money series by the GDP deflator. The fourth difference of the log of RM4 is shown in Figure 3 along with the fourth difference of this series which is found to be important in the Results section. "Real Stock Price" index (RSP) is created by dividing the stock market index by the GDP deflator, the fourth difference of the logarithm of this is shown in Figure 3 along with nominal US stock price index - the Standard and Poor's 500 common stock index - with the same transformation applied.

\section{Modelling the Probability of Expansion}

A fuller account of the methodology used to construct our composite leading indicator is presented in BJOS. A brief outline is presented here to clarify the subsequent discussion of the results. Let $\omega_{t}$ represent a complete history of all possible information about the state of the economy up to and including period $t$. It is assumed that given $\omega_{\mathrm{t}}$ there is no uncertainty in classifying period $t$ into one of expansion or contraction. If $p\left(\omega_{t}\right)$ is the probability that period $t$ is one of expansion given $\omega_{t}$ then either $p\left(\omega_{t}\right)=1$ or $p\left(\omega_{t}\right)=0$. Furthermore, it is assumed that the probability $p\left(\omega_{t-1}\right)$ of period $t$ being one of expansion given the complete history up and including period $t$ 1 is well-defined for all periods. A coincidental indicator of regimes is a model based on incomplete histories that approximates the true indicator $p\left(\omega_{t}\right)$. A oneperiod ahead indicator is a model based on incomplete histories up to and including period $t$-1 which approximates the true indicator $p\left(\omega_{t-1}\right)$. In this paper we concentrate on the task of constructing a one-period ahead indicator. To this end we consider models of the form

$$
p_{\mathrm{t}}=l f\left(\beta^{\prime} \boldsymbol{x}_{\mathrm{t}-1}\right)
$$

where If is the logistic function i.e. If $(\mathrm{z})=\exp (\mathrm{z}) /[1+\exp (\mathrm{z})], \beta$ is a vector of coefficients and $\boldsymbol{x}_{\mathrm{t}-1}$ is a vector of variables observed before or in period $t-1$. Let $y_{\mathrm{t}}$ 
indicate the regime at time $t$ so that $y_{\mathrm{t}}=1$ if period $t$ is one of expansion and $y_{\mathrm{t}}=0$ if period $t$ is one of contraction. Given a set of observations $y_{\mathrm{t}}$ on regimes and $\boldsymbol{x}_{\mathrm{t}}$ on leading indicators for $t=1, \ldots, \mathrm{T}$, then the likelihood of the model is

$$
L=\Pi_{1} l f\left(\boldsymbol{x}_{\mathrm{t}}\right) \Pi_{0}\left(1-l f\left(\boldsymbol{x}_{\mathrm{t}}\right)\right)
$$

where the first product is taken over all periods for which $y_{\mathrm{t}}=1$ and the second product is taken over all periods for which $y_{\mathrm{t}}=0$. Constructing a composite indicator involves choosing $\boldsymbol{x}_{\mathrm{t}}$ and finding the maximum likelihood estimate of $\beta$. Selection of $\boldsymbol{x}_{\mathrm{t}}$ involves the prior selection of potential variables followed by an automated search algorithm that aims to minimise the Schwartz's Information Criterion (SIC), namely

$$
\mathrm{SIC}=-2 \log L+n \log T
$$

where $L$ is the likelihood, $n$ is the number of estimated parameters and $T$ is the number of observations in the sample used for estimation. The advantage of such penalised likelihood procedures is that they tend to lead to better approximations of true structures than the penalty free likelihood in a wide range of circumstances.

The automated search procedure works as follows. We select $a$ priori a set of $K$ variables $x_{1 t}, \ldots, x_{\mathrm{Kt}}$. The algorithm then finds that subset of $K-1$ variables that gives the lowest value of SIC over the sample period. This subset is then used in the next stage and the omitted variable is excluded. Working with the selected set of $\mathrm{K}-1$ variables the algorithm considers all subsets of $K-2$ variables and chooses that which gives the lowest SIC value. The omitted variable is excluded and this continues until there is only one variable left. At the final stage the algorithm has $K$ selected subsets with associated SIC values and of these it chooses that subset which gives the lowest SIC value. It is to be stressed that the algorithm is not an exhaustive search of all subsets of the original $K$ variables. A major implication of this partial search is that the final selection is not guaranteed to be that subset which minimises SIC; a variable maybe rejected prematurely. Furthermore, this implies that the inclusion or exclusion of one or more variables can alter the selected set even if the included or excluded variables do not appear in the final selection. A further complication arises from the very real possibility of getting a spurious "perfect" fit in which the model is able to correctly classify all points in the sample set. 
All in all, the selection of the prior set of variables is non-trivial and in practice requires us to draw on prior experience and expectations. In particular, it is possible to substantially improve SIC values by imposing appropriate restrictions on parameters. For example, the use of "real" variables and the removal of price and inflation variables have proved to be fruitful.

\section{Results}

Each variable is "normalised" prior to estimation. To normalise a variable $\boldsymbol{x}$, the mean $\boldsymbol{a}$ and standard deviation $\boldsymbol{s}$ are calculated over the estimation period and $\boldsymbol{x}$ is replaced by $\boldsymbol{x}^{\prime}=(\boldsymbol{x}-\boldsymbol{a}) / \boldsymbol{s}$. The results presented in Table 3 are based on an estimation period running from 1966 Q1 to 1997 Q1 giving 125 observations. Data from 1963 Q1 to 1965 Q4 were used for various lag and difference operations. Data from 1997 Q2 to 1999 Q2 were used for out of sample tests of the models. Table 3 gives the estimated coefficients for the normalised variables together with summary statistics (RMSE, -2LogL, SIC) and error counts for a number models. Errors counts are given for In Sample (1966 Q1 to 1997 Q1) and Out of Sample (1997 Q2 to 1999 Q2). In each case the error counts are given separately for expansion and contraction periods. In reporting the error counts we describe the count as a percentage as well as the numerical count. For example, the Model A in sample error count for expansionary periods is $2 \%(3 / 102)$ indicating that the rounded down percentage is $2 \%$ and the count is 3 out of 102 .

To calculate these error counts, the estimated probability $p\left(\boldsymbol{x}_{\mathrm{t}}\right)$ is converted into an expansion forecast if $p\left(\boldsymbol{x}_{\mathrm{t}}\right)>0.5$. The forecast is of recession if $p\left(\boldsymbol{x}_{\mathrm{t}}\right) \leq 0.5$. Although this 0.5 rule is natural, there are also arguments to suggest that the rule for expansion prediction should be if $p\left(\boldsymbol{x}_{\mathrm{t}}\right)>\boldsymbol{p}$, where $\boldsymbol{p}$ is the proportion of expansionary periods in the sample. See BJOS for a discussion of this issue. To reflect the latter, and following BJOS, an estimated probability is considered to fall in the uncertain region when it is greater than 0.5 but less than $\boldsymbol{p}$, with $\boldsymbol{p}=0.816$ for this sample period. The reported error counts are based on the 0.5 rule, but we offer the uncertain count to give a feeling for the impact of using the $\boldsymbol{p}$-rule. The reader may wish to look at the plots in Figures 4 and 5 with the $p$-rule in mind. 
We illustrate the stages of our modelling by the results presented in Table 3. Initially a range of nominal variables were tried in combination with the inflation series (the fourth difference of the log of the GDP deflator), both with lags up to eight. Of these, the single nominal series that captured the three recession phases with the lowest SIC was M4 together with inflation. The resulting model is shown as Model A in Table 3 and the resulting regime probabilities are shown in Figure 4. Model A shows that two lags have been selected for M4 and inflation (though not strictly the same lags) with coefficients of similar magnitudes and opposite signs ,so we find a definite case for creating real M4 (RM4). Analogous results were obtained for nominal stock prices with inflation though this was poor at selecting the business cycle phases. Nominal TBY consistently survived as did the term structure with inflation.

We next go on to model RM4 with a combination of other variables. The main surprise from the models that include RM4, is in almost all cases they suffered from spurious perfect fit. To remove these spurious perfect fit models we had to impose a number of restrictions. Essentially we used specific lags of variables suggested by other models $e$.g. using Stock Prices lagged one period.

In Model B we add the real stock prices (RSP), the term structure (TS) and inflation to RM4. The first attempt to construct B led to a spurious perfect fit but suggested the imposition of a selection of variables. These variables were $\Delta_{4} \log (\mathrm{RSP})_{-1}$ (the annual difference of the log of real stock prices lagged one period), $\Delta_{4} \log (\mathrm{RM} 4)_{-1}, \Delta_{4} \log (\mathrm{RM} 4)_{-5}$ (the annual difference of real M4 lagged over one and five periods), $\mathrm{TS}_{-1}$ (the term structure lagged one period) and $\Delta_{4} \log (\mathrm{PI})_{-5}$ (the rate of inflation lagged five periods). This model reduces the SIC in comparison to Model A but predicts the 1990s recession too early as shown in the top right-hand chart of Figure 4. We noticed in B that the term structure variable was matched by an inflation variable with a negative sign. The latter lead us to experiment with the "real" term structure (with lags one to eight) this produces Model C. This model reduces the SIC but increases the error count in expansions as a spike reappears in 1983 (see bottom left-hand chart in Figure 4).

A surprising feature was that RM4 consistently appeared with lags one and five and with opposite signed coefficients on the two lags. This led us to experiment 
with the second difference of RM4. Therefore a new variable is created by taking the fourth difference of $\Delta_{4} \log (\mathrm{RM} 4)$ giving $\Delta_{4} \Delta_{4} \log (\mathrm{RM} 4)_{-1}$. The outcome is Model D which reduces SIC but increases the error count in contractions as it is not picking up enough of the 1990s recession, see bottom right-hand chart in Figure 4.

Model E includes nominal treasury bill yield (TBY - initially with up to eight lags) and the second difference of RM4. TBY is selected with one lag which reduces the SIC but increases the in sample error count for expansions. We move then to include the RSP variable which produces Model F, this time lag five of TBY is also selected with a negative normalised coefficient. The SIC is improved upon but not all the 1990s recession is adequately predicted, see top right-hand chart of Figure 5.

Building on Models $\mathrm{A}$ to $\mathrm{E}$, we then examine the role of international variables. US stock prices and both US and German and interest rate series were considered, but only US stock prices and German interest rates survived the selection process. Model G adds the US S\&P 500 nominal index to the variables of Model F to reflect the open nature of the UK stock market. Model G selects real stock prices for the UK with a longer lag (compared to previous models) at three and US stock returns are selected at lag four with a negative coefficient; only lag one is selected for TBY. The SIC is reduced but the prediction of the 1990s recession is again inaccurate, see bottom left-hand chart of Figure 5. A further problem with this model is an inaccurate count out of sample for expansions.

Finally Model H takes Model G and adds to it German short-term interest rates (the FIBOR with lags up to eight). However, this variable eliminates the effect of both stock markets and drastically reduces the SIC giving the best overall in sample error count. Most significant from Figure 5 (bottom right-hand chart) is that the 1990s recession is predicted for effectively its whole duration by the addition of this variable.

Model $\mathrm{G}$ is the only model that had one out of sample error with estimated probability of 0.16 in 1998 Q3. Although GDP did not fall at this time, there was a good deal of concern at the end of 1998 that the UK was entering into a recession. Indeed GDP "flattened off” in the fourth quarter of 1998 and the first quarter of 1999, while industrial production actually fell in these two quarters. While the detailed 
forecasts are wrong, particularly that for the second quarter of 1998, this model is more in line with the experience of 1998 than many of the alternative models which give no hint of a recession in 1998.

SIC, error counts and subjective inspection of the probability plots suggest Model $\mathrm{H}$ is preferable overall to other models. The use of $\Delta_{4} \Delta_{4} \log (\mathrm{RM} 4)_{-1}$ seems to have smoothed the probability series just before the third recession, but emphasized the "spike" in the 1983. The German interest rate is the most significant international variable of those examined and helps largely explain the 1990s recession in the UK.

\section{Conclusion}

In this paper we offer dates for classifying UK GDP into classical cycles of expansion and recession. We also construct a composite leading indicator for this cycle using the methodology developed in BJOS. Not withstanding the difficulties in dating cycles and constructing leading indicators, we believe that the results of our efforts are of interest. In particular, the results suggest that German short-term interest rates complement UK real broad money and the treasury bill yield, adding predictive information for regimes in UK GDP compared to that available in domestic variables on their own. 


\begin{tabular}{|c|c|c|c|c|c|c|c|c|}
\hline \multicolumn{9}{|c|}{ Model } \\
\hline Variable & $\mathbf{A}$ & B & $\mathbf{C}$ & D & $\mathbf{E}$ & $\mathbf{F}$ & $\mathbf{G}$ & $\mathbf{H}$ \\
\hline Intercept & $3.597(4.55)$ & $4.889(3.97)$ & $4.078(4.52)$ & $3.773(4.45)$ & $3.834(4.55)$ & $4.706(4.02)$ & $4.582(4.12)$ & $8.268(2.904)$ \\
\hline$\Delta_{4} \log (\mathrm{M} 4)_{-2}$ & $3.742(3.26)$ & & & & & & & \\
\hline$\Delta_{4} \log (\mathrm{M} 4)_{-5}$ & $-4.983(-3.81)$ & & & & & & & \\
\hline$\Delta_{4} \log (\mathrm{RSP})_{-1}$ & & $1.879(2.26)$ & $1.762(2.41)$ & $1.691(2.65)$ & & $2.376(2.40)$ & & \\
\hline$\Delta_{4} \log (\mathrm{RSP})_{-3}$ & & & & & & & $2.357(2.63)$ & \\
\hline$\Delta_{4} \log (\mathrm{RM} 4)_{-1}$ & & $4.172(3.21)$ & $3.284(3.64)$ & & & & & \\
\hline$\Delta_{4} \log (\mathrm{RM} 4)_{-5}$ & & $-4.167(-3.13)$ & $-4.401(-4.04)$ & & & & & \\
\hline$\Delta_{4} \Delta_{4} \log (\mathrm{RM} 4)_{-1}$ & & & & $3.603(4.02)$ & $2.699(3.61)$ & $2.978(3.12)$ & $3.929(2.96)$ & $5.584(2.86)$ \\
\hline TBY $_{-1}$ & & & & & $-2.475(-3.80)$ & $-2.226(-2.62)$ & $-2.506(-3.28)$ & $-3.857(-2.61)$ \\
\hline $\mathrm{TBY}_{-5}$ & & & & & & $-1.619(-2.45)$ & & \\
\hline FIBOR $_{-1}$ & & & & & & & & $-3.858(-2.48)$ \\
\hline$\Delta_{4} \log (\mathrm{USS} \& \mathrm{P})_{-4}$ & & & & & & & $-1.954(-2.74)$ & \\
\hline $\mathrm{TS}_{-1}$ & & $2.088(2.79)$ & & & & & & \\
\hline$\Delta_{4} \log (\mathrm{PI})_{-1}$ & $-5.112(-3.11)$ & & & & & & & \\
\hline$\Delta_{4} \log (\mathrm{PI})_{-3}$ & $3.12(2.34)$ & & & & & & & \\
\hline$\Delta_{4} \log (\mathrm{PI})_{-5}$ & & $-3.11(-2.87)$ & & & & & & \\
\hline $\mathrm{RTS}_{-5}$ & & & $3.262(3.76)$ & $2.459(3.71)$ & & & & \\
\hline \multicolumn{9}{|l|}{ Summary Statistics } \\
\hline RMSE & 0.2454 & 0.2047 & 0.2084 & 0.2223 & 0.2381 & 0.2001 & 0.1915 & 0.1631 \\
\hline$-2 \log \mathrm{L}$ & 47.26 & 31.8 & 35.72 & 39.87 & 43.96 & 30.9 & 30.79 & 20.38 \\
\hline SIC & 71.41 & 60.77 & 59.86 & 59.19 & 58.44 & 55.04 & 54.93 & 39.69 \\
\hline \multicolumn{9}{|l|}{ Errors In Sample } \\
\hline Expansions & $2 \%(3 / 102)$ & $1 \%(2 / 102)$ & $2 \%(3 / 102)$ & $2 \%(3 / 102)$ & $4 \%(5 / 102)$ & $1 \%(2 / 102)$ & $2 \%(3 / 102)$ & $1 \%(2 / 102)$ \\
\hline Contractions & $34 \%(8 / 23)$ & $21 \%(5 / 23)$ & $21 \%(5 / 23)$ & $30 \%(7 / 23)$ & $21 \%(5 / 23)$ & $21 \%(5 / 23)$ & $17 \%(4 / 23)$ & $17 \%(4 / 23)$ \\
\hline Uncertain & $(18 / 125)$ & $(10 / 125)$ & $(9 / 125)$ & $(14 / 125)$ & $(8 / 125)$ & $(9 / 125)$ & $(6 / 125)$ & $(7 / 125)$ \\
\hline \multicolumn{9}{|l|}{ Errors Out of Sample } \\
\hline Expansions & $0 \%(0 / 9)$ & $0 \%(/ 9)$ & $0 \%(/ 9)$ & $0 \%(/ 9)$ & $0 \%(0 / 9)$ & $0 \%(/ 9)$ & $11 \%(1 / 9)$ & $0 \%(0 / 9)$ \\
\hline Contractions & $0 \%(0 / 0)$ & $0 \%(0 / 0)$ & $0 \%(0 / 0)$ & $0 \%(0 / 0)$ & $0 \%(0 / 0)$ & $0 \%(0 / 0)$ & $0 \%(0 / 0)$ & $0 \%(0 / 0)$ \\
\hline Uncertain & $(0 / 9)$ & $(0 / 9)$ & $(0 / 9)$ & $(0 / 9)$ & $(0 / 9)$ & $(0 / 9)$ & $(0 / 9)$ & $(0 / 9)$ \\
\hline
\end{tabular}

Table 3: Illustrative Results 
Probability

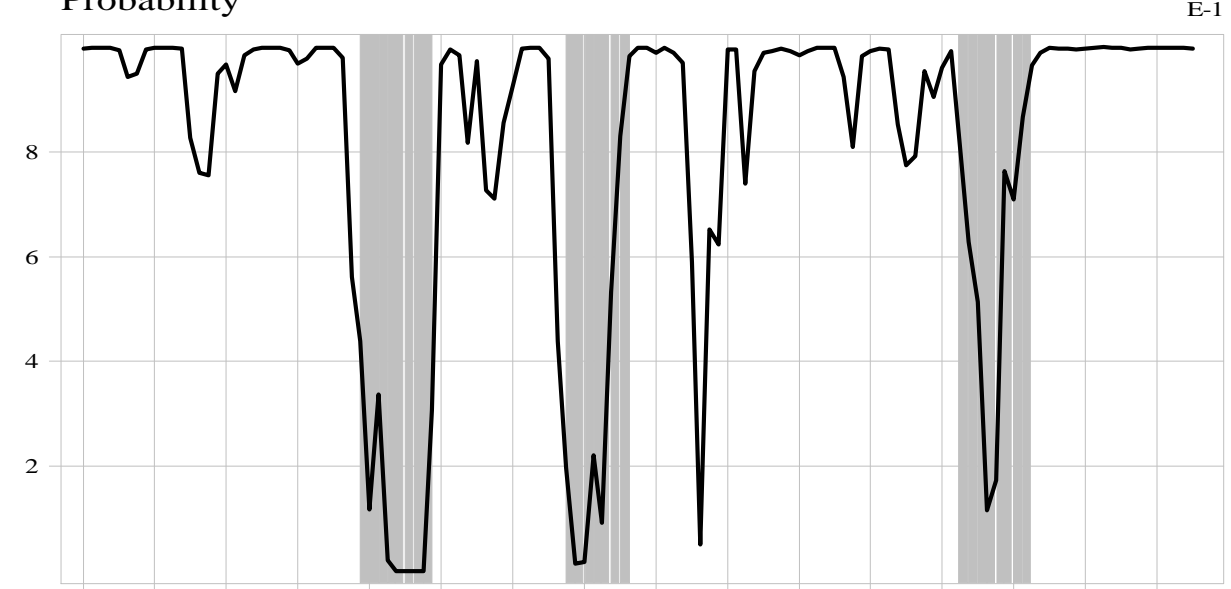

R4 Regimes of GDP

(A) Nominal M4 and inflation

Probability
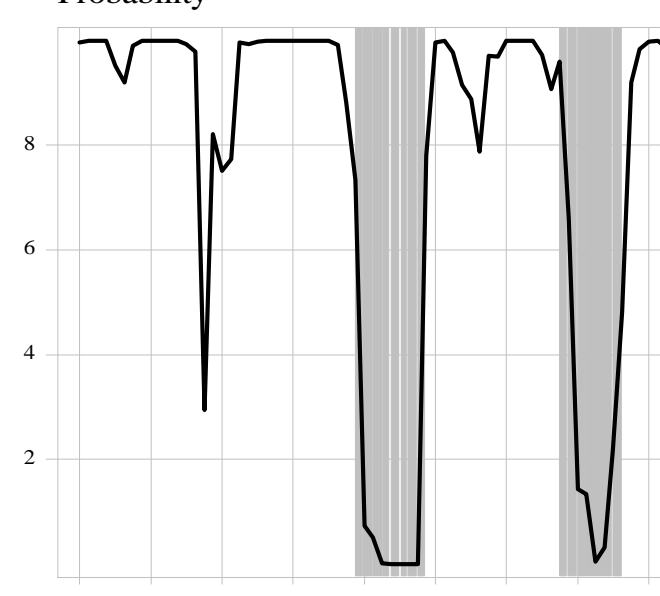

$66 \quad 68$ R4 Regimes of GDP

(C) Real M4, real SP and real term structure
E-1

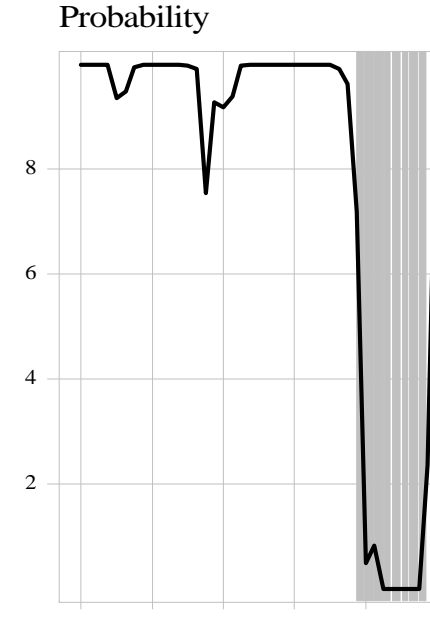

66

\section{a}

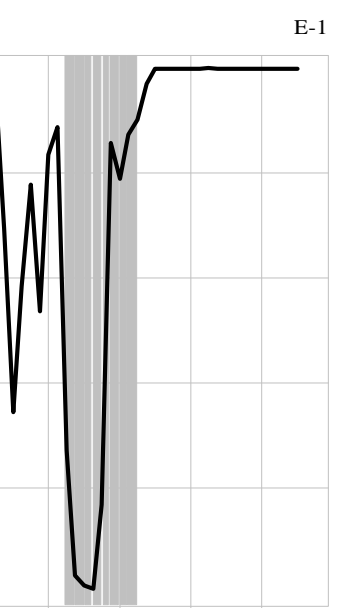

${ }^{78}{ }^{80}{ }^{80}$ Regimes of GDP $^{84}$

90

$\begin{array}{rrr}92 \quad 94 \quad 96 & \\ \quad & \text { Time }\end{array}$

Probability

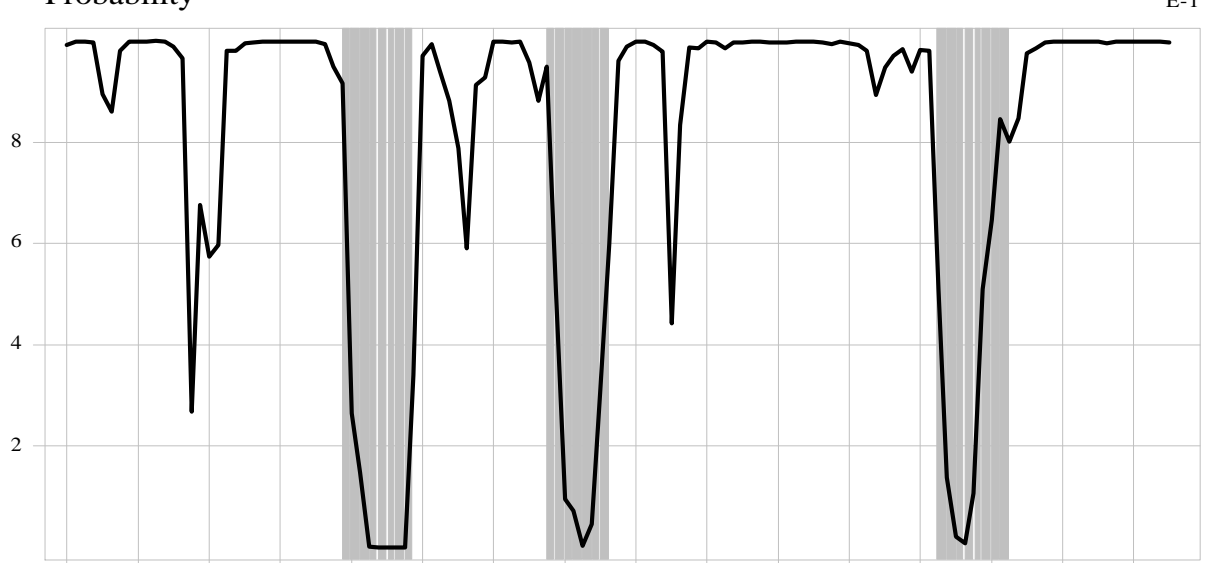

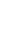

(D) $4^{\text {th }}$ difference of Real M4, real SP and real term structure Figure 4: Filter Probability Charts 


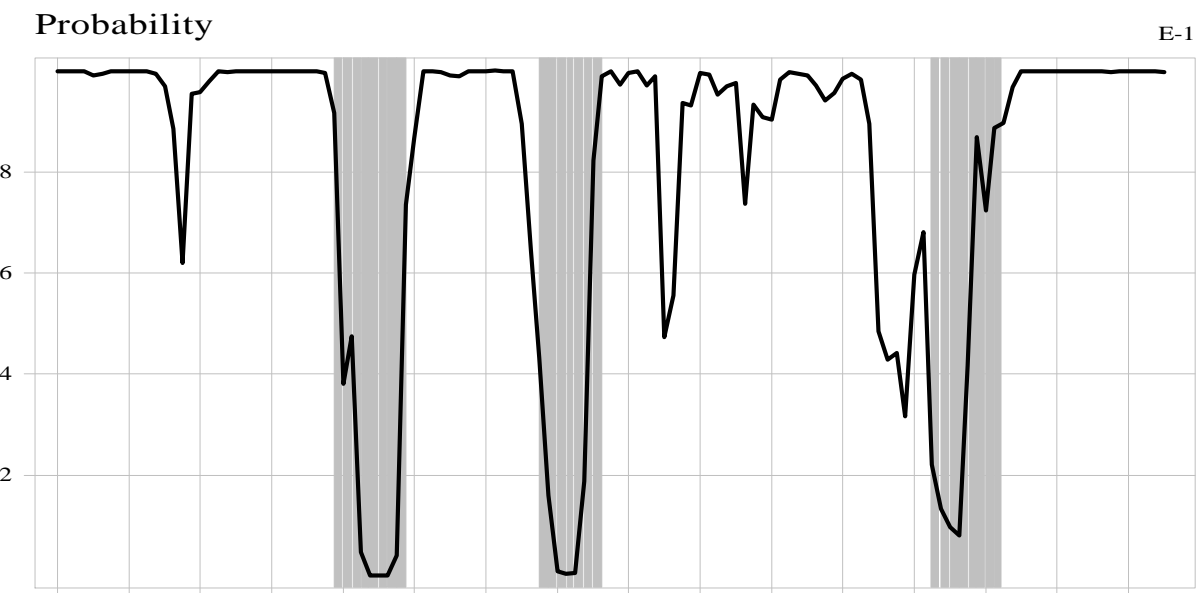

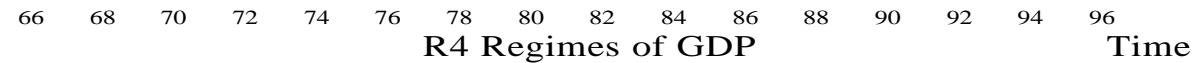
(E) Real M4 and nominal TBY

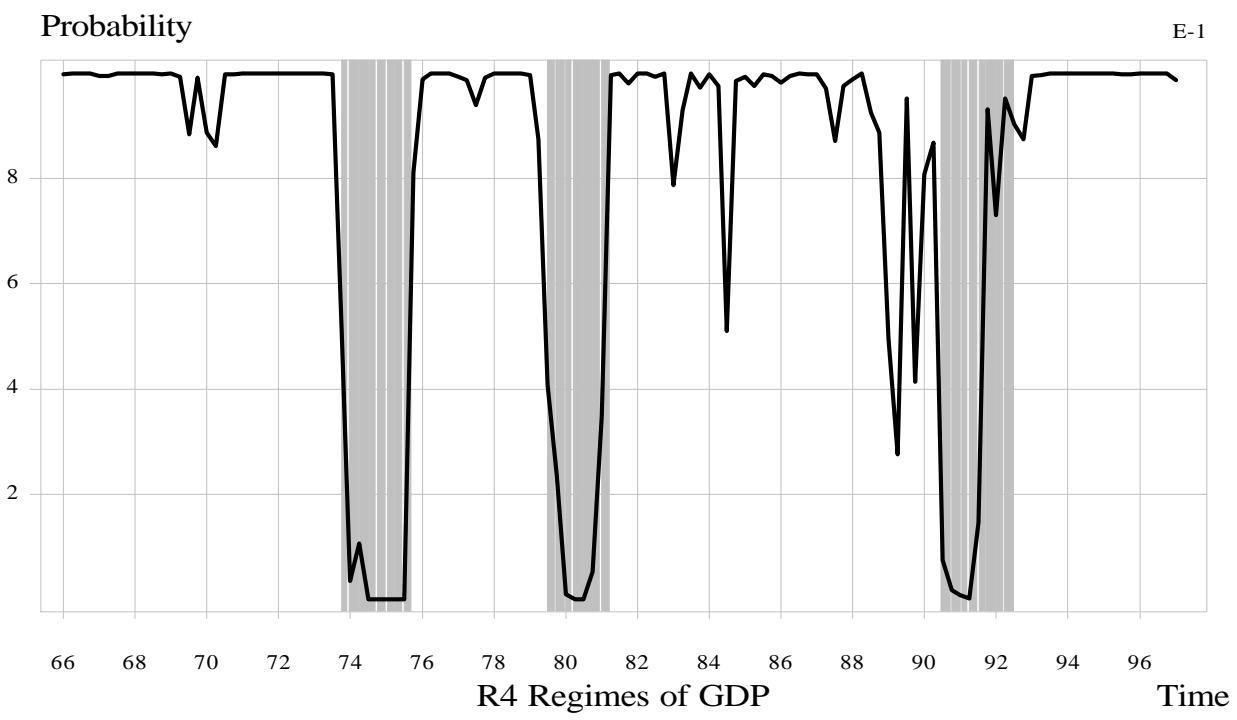

(G) Real M4, real SP, US S\&P 500 and nominal TBY
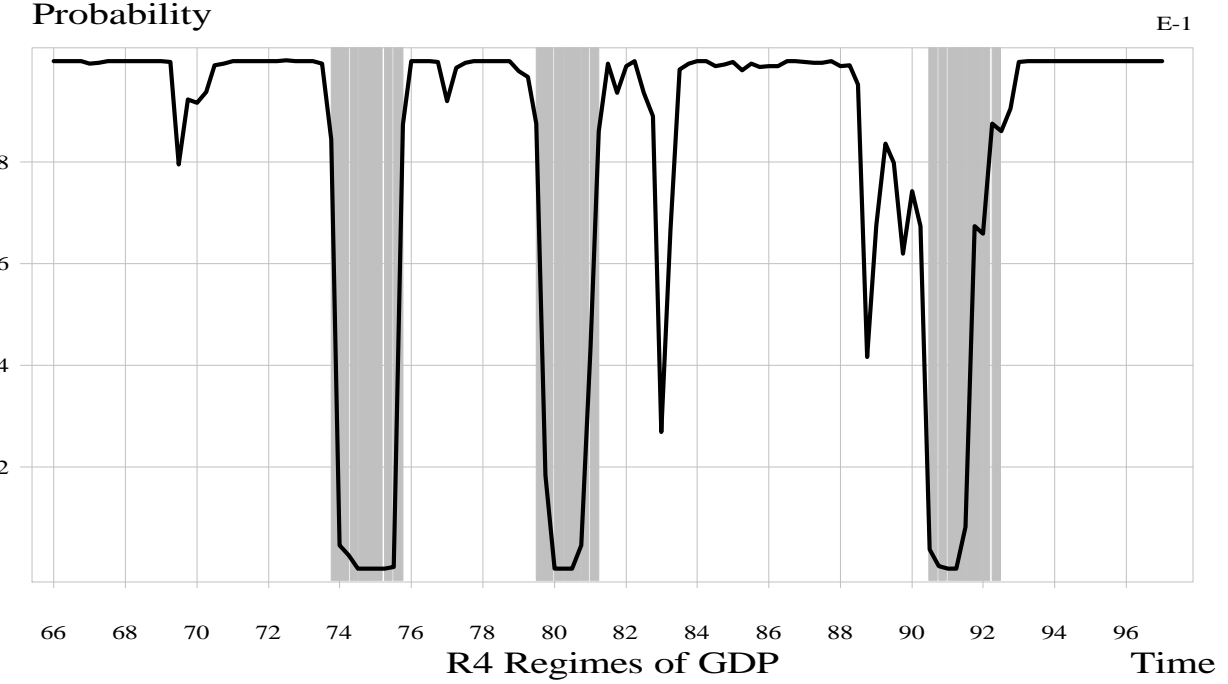

(F) Real M4, real SP and nominal TBY
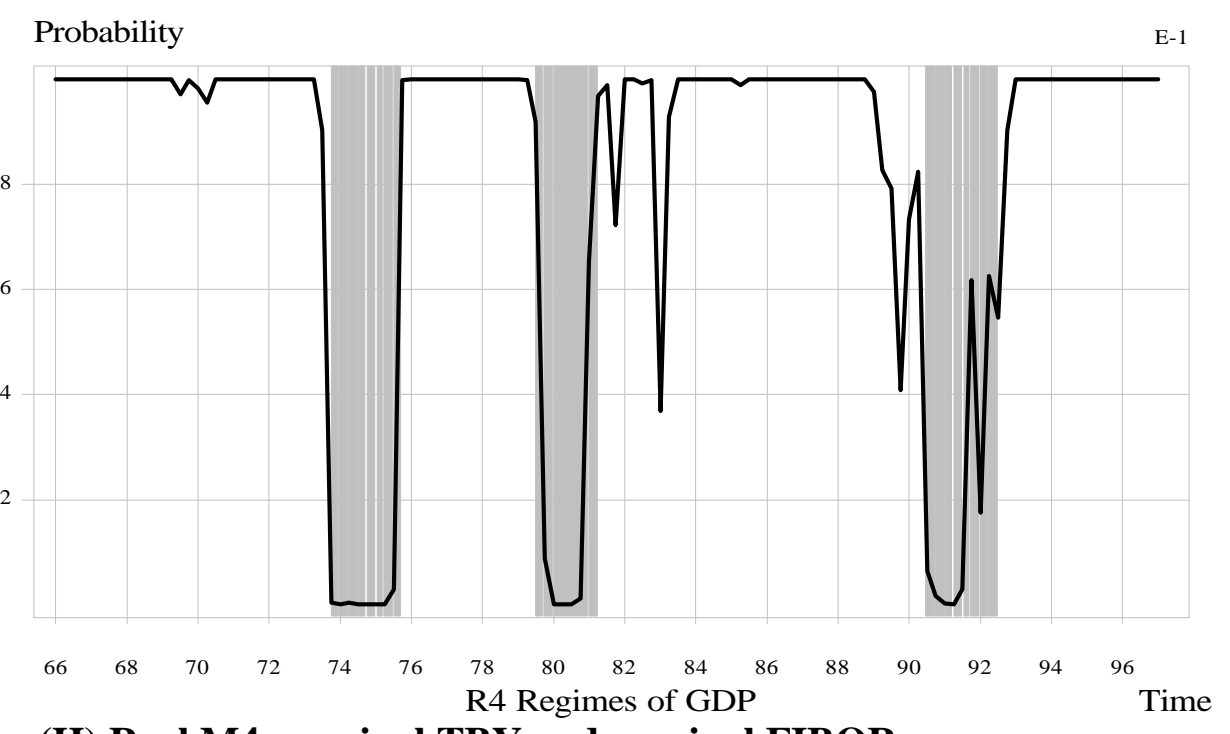

R4 Regimes of GDP
(H) Real M4, nominal TBY and nominal FIBOR

Figure 5: Filter Probability Charts 


\section{A. Data Appendix}

\begin{tabular}{|c|c|c|c|c|c|}
\hline Variable & Full Name & Sample & Source/ code & $\begin{array}{l}\text { SA or } \\
\text { NSA* }\end{array}$ & Transform \\
\hline GDP & Gross Domestic Product index: Constant market prices $1995=100$ & $55 q 1-99 q 2$ & ONS/ YBEZ & SA & D4 of Log \\
\hline PI & GDP Gross Value Added at basic prices: Implied deflator1995=100 & $55 q 1-99 q 2$ & ONS/ CGBV & SA & D4 of $\log$ \\
\hline INF & $\begin{array}{ll}\text { Inflation Rate } \\
\end{array}$ & $56 q 1-99 q 2$ & $100 *(\log (\mathrm{PI})-\log (\mathrm{PI}(-4)))$ & SA & - \\
\hline SP & FT actuaries all share index (10 April 1962=100) & $63 q 1-99 q 3$ & ONS/ AJMA & NSA & D4 of Log \\
\hline RSP & Real stock prices & $63 q 1-99 q 3$ & $\mathrm{SP} / \mathrm{PI}$ & NSA & D4 of $\log$ \\
\hline DY & FT actuaries all share index: dividend yield \% & $63 q 1-99 q 3$ & ONS/ AJMD & NSA & None \\
\hline M4 & Money stock M4 (end period): level \#m & $63 q 1-99 q 2$ & ONS/ AUYN & $\mathrm{SA}$ & D4 of $\log$ \\
\hline RM4 & Real M4 & $63 q 1-99 q 2$ & M4 / PI & SA & D4 of Log \\
\hline TBY & Treasury Bills 3 month yield & $60 q 2-99 q 3$ & ONS/ AJRP & NSA & None \\
\hline LR & BGS: long-dated (20 years): Par yield - \% per annum & $57 q 1-99 q 2$ & ONS/ AJLX & NSA & None \\
\hline TS & Term Structure & $60 q 2-99 q 2$ & LR - TBY & NSA & None \\
\hline RTS & Real Term Structure & $60 q 2-99 q 2$ & LR-TBY-INF & NSA & None \\
\hline US S\&P & US Standard \& Poor's index of 500 common stocks(monthly average) & $60 q 1-99 q 3$ & Datastream & NSA & D4 of $\log$ \\
\hline USFF & US Federal Funds interest rate & $60 q 1-99 q 3$ & OECD & NSA & None \\
\hline FIBOR & German Frankfurt inter-bank offered rate & $60 q 1-99 q 3$ & OECD & NSA & None \\
\hline CONS & Consumers' Expenditure 1990 Prices & $55 q 1-99 q 2$ & OECD & SA & D4 of Log \\
\hline $\mathrm{USXCH}$ & GB/US Dollar Exchange Rate month average / Quantum & $60 q 1-99 q 3$ & OECD & NSA & - \\
\hline HCPI & CPI Housing / Index publication base & $62 q 1-99 q 2$ & OECD & NSA & D4 of Log \\
\hline $\mathrm{HS}$ & Housing Starts & $57 q 1-98 q 1$ & ONS/ CTOZ & SA & D4 of $\log$ \\
\hline \multirow[t]{2}{*}{$\mathrm{CBIO} * *$} & \multirow[t]{2}{*}{ CBI Change in Optimism } & $59 q 1-71 q 4$ & ONS/ DKDK & SA & \multirow[t]{2}{*}{ None } \\
\hline & & $72 q 1-98 q 4$ & Datastream & NSA & \\
\hline
\end{tabular}

* SA = Seasonally Adjusted and NSA = Not Seasonally Adjusted.

** The CBI Industrial Trend Survey was only conducted three times a year between 1959 and 1971 and the ONS have interpolated these values to give a quarterly series before seasonally adjusting it with X-11. After this the author uses a regression with seasonal dummies to seasonally adjust the data.

Table A.1: Data descriptions with sample period, source and transformations 


\section{References}

Andreou, E., Osborn, D. R. and Sensier, M. (1999), 'A comparison of the statistical properties of financial variables in the USA, UK and Germany over the business cycle', Discussion paper 9909, School of Economic Studies, University of Manchester; Manchester School, forthcoming.

Artis, M. J., Kontolemis, Z. G. and Osborn, D. R. (1997), 'Business cycles for G7 and European countries', Journal of Business, Vol. 70, pp. 249-279.

Binner, J.M., Fielding, A. and Mullineux, A.W. (1999), 'Divisia money in a composite leading indicator of inflation', Applied Economics, Vol.31, No.8, pp.10211031.

Birchenhall, C. R., Jessen, H., Osborn, D. R. and Simpson, P. (1999), 'Predicting US Business-Cycle Regimes', Journal of Business and Economic Statistics, Vol. 17, no. 3, 313-323.

Boldin, M. D. (1994), 'Dating business cycle turning points', Journal of Business, Vol. 67, pp. 97-131.

Bry, G. and Boshcan, C. (1971), Cyclical Analysis of Time Series: Selected Procedures and Computer Programs, New York, NBER.

Burns, A. F. and Mitchell, W. C. (1946), Measuring Business Cycles, New York, NBER.

Camba-Mendez, G., Kapetanios, G., Smith, R., and Weale, M. (1999), 'An Automatic Leading Indicators of Economic Activity: Forecasting GDP Growth for European Counties', NIESR Discussion Paper No. 149.

Conference Board, (1998), Business Cycle Indicators. New York. 2 (February) no.3.

Dow, C. (1998). Major Recessions: Britain and the World, 1920-1995. Oxford University Press, Oxford.

Estrella, A. and Mishkin, F. S. (1998), 'Predicting U.S. Recessions: Financial Variables as Leading Indicators', Review of Economics and Statistics, Vol. 80, pp. 4561. 
Green, G. R. and Beckman, M. A. (1993), 'Business cycle indicators: upcoming revisions of composite leading indicators', Survey of Current Business, October, Vol. 73, pp. 44-51.

Harding, D. and Pagan, A.R. (1999), 'Dissecting the Cycle', Melbourne Institute Working Paper No. 13/99.

Moore B. (1993), 'A Review of CSO Cyclical Indicators', Economic Trends, No. 477, July, pp. 99-107.

Nilsson, R. (1987). OECD leading indicators. OECD Economic Studies, 9, 105-146.

Plosser, C. I. and Rouwenhorst, K. G. (1994). 'International term structures and real economic growth', Journal Of Monetary Economics, Vol. 33, No. 1, pp. 133-55.

Roma, A. and Torous, W. (1997). 'The cyclical behavior of interest rates', Journal of Finance, Vol. 52, No. 4, pp. 1519-42.

Simpson PW, Osborn DR and Sensier M. 1999. Modelling Business Cycle Movements in the UK Economy. School of Economic Studies Discussion Paper Series, University of Manchester, No. 9908.

Stock, J. H. and Watson, M. W. (1991), 'A probability model of the co-incident indicators', in G. Moore and K. Lahiri, eds, Leading Economic Indicators, Cambridge University Press, pp.63-90.

Stock, J. H. and Watson, M. W. (1993), 'A procedure for predicting recessions with leading indicators: Econometric issues and recent experience', in J.H. Stock and M.W. Watson, eds., Business Cycle Indicators and Forecasting, Chicago: University of Chicago Press, pp.95-156. 